\title{
Operational eruption forecasting at high-risk volcanoes: the case of Campi Flegrei, Naples
}

\author{
Jacopo Selva ${ }^{1 *}$, Warner Marzocchi $^{2}$, Paolo Papale ${ }^{3}$ and Laura Sandri ${ }^{1}$
}

\begin{abstract}
High risk volcanic events are commonly preceded by long periods of unrest during which scientists are asked to provide near real-time forecasts. The rarity of such events, inaccessibility of the underground volcanic system, non-linear behaviors, and limited datasets constitute major sources of uncertainty. In order to provide reasoned guidance in the face of uncertainties, monitoring observations and conceptual/theoretical models must be incorporated into a formal and structured probabilistic scheme using evidence science principles. As uncertainty and subjectivity are inescapable components of volcanic hazard forecasts, they must be dealt with and clearly communicated to decision-makers and society. Here, we present the set-up of an automated near-real-time tool for short-term eruption forecasting for Campi Flegrei caldera (CFc), Italy. The tool, based on a Bayesian Event Tree scheme, takes account of all the available information, and subjectivity of choices is dealt through a 5-year-long elicitation experiment with a team of about 30 of the major experts of the geological history, dynamics and monitoring of CFc. The tool provides prompt probabilistic assessment in near real-time, making it particularly suitable for tracking a rapidly evolving crisis, and it is easily reviewable once new observations and/or models become available. The quantitative rules behind the tool, which represent the group view of the elicited community of experts, are defined during a period of quiescence, thus allowing prior scrutiny of any scientific input into the model, and minimizing the external stress on scientists during an actual emergency phase. Notably, the results also show that CFc may pose a higher threat to the city of Naples than the better-known Mount Vesuvius.
\end{abstract}

Keywords: Volcanic hazard, Eruption forecasting, Aleatory and epistemic uncertainty, Expert elicitation, Bayesian event tree

\section{Background}

The Campi Flegrei caldera $(\mathrm{CFc})$ directly threatens a population of several hundred thousands who lives inside the caldera, and the city of Naples itself $(\sim 1$ million inhabitants), just outside the caldera. The latest eruption occurred in 1538, 4,000 years after the previous one that closed a period of intense eruptive activity (Orsi et al.1996). The 1538 eruption was preceded by uplift of the caldera floor, seismic swarms, and visible variations in fumarolic output that lasted at least several decades (Guidoboni and Ciucciarelli 2011). The eruption was explosive and resulted in the construction of the new hill of Monte Nuovo in the western caldera sector (di Vito et al. 1987). After about 4 centuries of caldera subsidence,

\footnotetext{
*Correspondence: jacopo.selva@bo.ingv.it

${ }^{1}$ Istituto Nazionale di Geofisica e Vulcanologia, sezione di Bologna, Via Donato Creti 12 - 40128 Bologna, Italy

Full list of author information is available at the end of the article
}

the present unrest started in the 1950's in the form of uprise of the caldera floor, seismic swarms, and changes in the flow, areal extent, and composition of fumaroles (Del Gaudio et al. 2010; Orsi et al. 1999). Periods of unrest concentrated at discrete periods of time, with major crises occurred in 1969-71 and 1982-84, the latter culminating in the evacuation of about 40,000 people from the city of Pozzuoli. Several other minor uplift periods have followed and continue, requiring the development of plans for scientific and civil protection operations. Such plans depend on the capability to interpret in real-time the observed dynamics and anticipate at least several days in advance the occurrence of a new eruption.

The extreme complexity of volcanic processes, nonlinearities, limited knowledge, and large number of degrees of freedom make deterministic predictions of volcanic system evolution extremely difficult, if not impossible

\section{是 Springer}

(c) 2012 Selva et al: licensee Springer. This is an Open Access article distributed under the terms of the Creative Commons Attribution License (http://creativecommons.org/licenses/by/2.0), which permits unrestricted use, distribution, and reproduction in any medium, provided the original work is properly cited. 
(Mader et al. 2006; Newhall and Dzurisin 1988). The additional complexity of decision-making and civil protection operations, especially in highly inhabited areas like CFc, requires evaluations to be made on time windows up to weeks, further amplifying the influence of uncertainties. As a consequence, a probabilistic approach is needed in order to manage the uncertainties and build a quantitative reference frame for managing scientific evidence within a rational decision-support process (Marzocchi and Woo 2009). However, past pre-eruptive data at CFc are not available, with the exception of the descriptive, macroscopic observations reported in the chronicles related to the 1538 eruption (Guidoboni and Ciucciarelli 2011). This is unfortunately a common situation at volcanoes globally. On the other hand, volcanologists have developed sophisticated conceptual and theoretical models and deployed advanced monitoring systems that provide relevant information about the status of the volcano. The problem is therefore to integrate such heterogeneous information into a formal probabilistic scheme for eruption forecast.

With such a purpose, we have set up a real-time tool for short-term eruption forecasting at CFc (BETEF_CF; see Figure 1A). The statistical model adopted is BET_EF (Bayesian Event Tree for Eruption Forecasting, Marzocchi et al. 2008). BET_EF is based on an Event Tree logic (Newhall and Hoblitt 2002), in which branches are logical steps from a general starting event (the onset of unrest, node 1), through specific subsequent events (the presence of magma driving the unrest, node 2), to the final outcome (the onset of an eruption, node 3), as reported in Figure 1A. BET_EF assesses probabilities at all nodes through Bayesian inference, including any possible source of information (theoretical beliefs, models, past data, and volcano monitoring), accounting for both aleatory and epistemic uncertainty. Then, the probability of eruption is calculated by multiplying the probabilities at each node. Using a simplified formalism the probability of eruption is given by

$$
\begin{aligned}
P(\text { eruption })= & P(\text { unrest }) \times P(\text { magma } \mid \text { unrest }) \\
& \times P(\text { eruption } \mid \text { magma, unrest })
\end{aligned}
$$

The method is described in details in (Marzocchi et al. 2008), and a free generic software tool is available online (Marzocchi et al. 2009), whose input could be defined by users in order to be applied to different volcanoes. A key feature of BET EF is that it automatically updates the forecast procedure depending on the occurrence of relevant anomalies in the volcanic activity. Whenever anomalies occur, BET_EF bases its forecast on the interpretation of the evolving monitoring measures (see Figure 1B). When only background activity is registered, the eruption forecast addresses only the expected long-term activity (see Figure 1C). The definition of what is background vs anomaly and the interpretation of anomalies represent the core of the analysis, i.e., the selection of the parameters of interest, and the quantitative definition of anomalies. For $\mathrm{CFc}$, the lack of previous pre-eruptive observations makes this analysis a necessary but rather subjective step that can be treated formally through expert opinion.

Expert opinion analysis is well established in many fields, including global political trends and economics, whenever decisions are made under limited knowledge and a high level of subjectivity (e.g., Cornish 1977), and in volcanology (Aspinall 2006; Neri et al. 2008). Weighting of experts varies, but it is a fundamental part of the elicitation process (e.g., Cook 1991), even though often equal-weighted procedures are still considered. Here we adopt a consensus-based expert scoring scheme and an innovative expert elicitation method that uses a structured and iterative process for developing consensus. This scheme resembles in its basic principles the Delphi method (e.g., Linstone and Turoff 1975), but it is targeted to overcome its main critics (vague questionnaire items, not equal treatment of respondents, significant number of dropouts, see Cook 1991 and references therein). In this process, expert opinion is weighted on the basis of mutual recognition among experts expressed through a regularly repeated blind procedure. Consensus, in our opinion, is indeed critical for the effective applicability of the results. Differing from most of expert elicitations (e.g., Neri et al. 2008), experts have been asked to select monitoring parameters and relative critical thresholds at each node of the event tree, instead of being asked directly for probabilities. In this way the individual and collective specialist knowledge is more effectively exploited, since the experts are asked to discuss and express themselves directly in their field of expertise: their knowledge enters the statistical model without the filter of personal sensitivity to probabilities, a subject that is unfamiliar to many volcanologists.

In the following, we report the set-up of BETEF_CF, based on (i) the results of a 5-year-long elicitation experiment and (ii) the analysis of CFc "background" activity. The applicability BETEF_CF is then demonstrated with a retrospective analysis of the observed unrest dynamics at CFc in the period 1981-2010.

\section{Development of the model BETEF_CF}

The goal of this paper is the set up of the model BET EF for CFc (hereinafter, BETEF_CF). This model estimates, in near-real time, the probability of occurrence in the time window $\left(t_{0}, t_{0}+\tau\right)$ of episodes of "unrest" (node 1 ), "magmatic unrest" (node 2) and "eruption" (node 3). Note that, in this formulation, we concentrate on the magmatic 


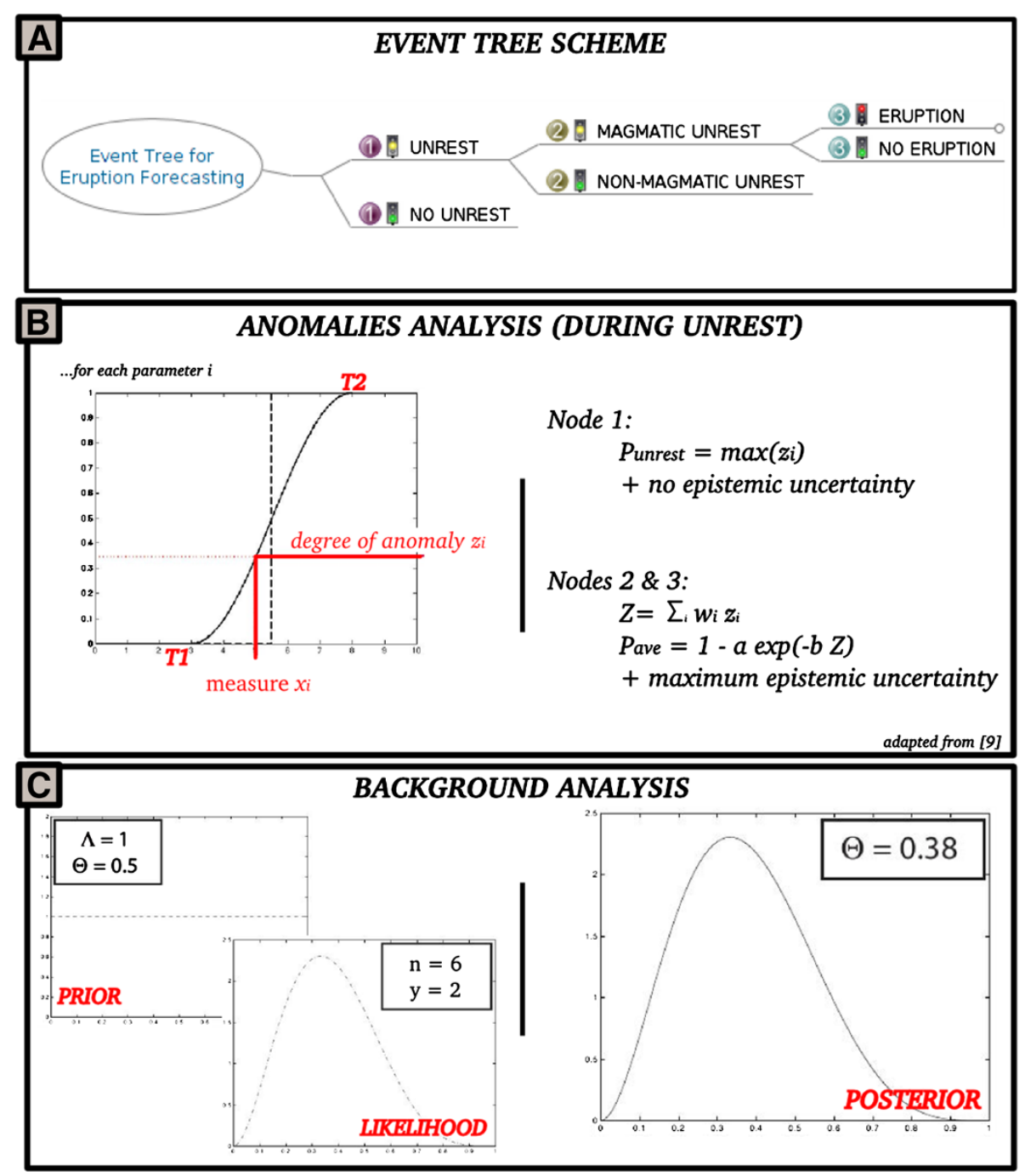

Figure 1 Schematic representation of the BET_EF model's settings (Marzocchi et al. 2008). In panel A, the three nodes of the Event Tree are represented. At each node, a Bayesian inference scheme is performed assuming a Beta distribution for the probability, both for the analysis of anomalies (panel B) and for the background analysis (panel C). BET_EF automatically switches between these two regimes, based on the observed state of unrest ( $P_{\text {unrest }}$ in panel $\mathbf{B}$ ). During unrest episodes, the model is based on the analysis of monitoring anomalies (panel $\mathbf{B}$ ), and it is set through the parameters $T 1, T 2$ and $w_{i}$, thresholds and weight of each monitoring measure, respectively. On the left, an example of fuzzy threshold is reported, where in $x$-axis the possible values for the parameter are reported, while in the $y$-axis is represented the degree of truth of the statement 'the parameter is anomalous', given a measurement equal to $x$. On the right, the basic principles of the transformation from anomalies to probabilities are reported; Bayesian inference is performed on the parameters $a$ and $b$. The background assessment is based on Bayesian inference on probabilities (panel $\mathbf{C}$ ), where theoretical models set prior distributions (through the average $\Theta$ and the equivalent number of data $\Lambda$ ), updated with the available past data (through the number of successes $y$ and of trials $n$ ). More details can be found in the text and in Marzocchi et al. (2008).

activity only. Of course, one of future developments will be the parallel treatment of non-magmatic phenomena, such as phreatic eruptions. For practical reasons, $\tau$ is set to 1 month, as for for Mt. Vesuvius (Marzocchi et al. 2004; Marzocchi et al. 2008). BETEF_CF switches between two distinct regimes, hereinafter referred to as short-term and long-term analyses, that is:

- When the state of unrest is detected at $t=t_{0}$ by BETEF_CF, all further probabilistic assessments are based on the analysis of changes in the volcanic system in rather short time frames (days to weeks). This situation is hereinafter referred to as short-term assessment. More precisely, monitoring anomalies are transformed (using a simple transfer function, see Figure 1B) into subjective probability distributions relative to the occurrence of "magmatic unrest" and "eruption", respectively. Here, the basic input for BETEF_CF is to define the anomalies to be accounted for at each node. This goal is achieved defining (i) a 
list of parameters of interest at each node and (ii) thresholds (in a fuzzy perspective) to identify anomalies for each of these parameters.

- When anomalies are not observed at time $t=t_{0}$, BETEF_CF considers the so-called background probabilities, hereinafter also referred to as long-term probabilities. Such long-term probabilities are based on theoretical models and the analysis of past data since 1980 (date after which anomalies can be reasonably defined with the available recordings from the monitoring system of $\mathrm{CFc}$ ), considering (i) the definition of unrest used for short-term assessments, (ii) the fact that no anomalies are recorded at $t=t_{0}$, and (iii) the fact that $\mathrm{CF}_{\mathrm{c}}$ has been experiencing a long-term uplift since the 1970s.

In both cases, the choice of the parameters and relative thresholds, at all the nodes, is the core of BETEF_CF, since it controls all probabilities assessments in the shortterm regime, and it defines the reference background status of CFc (no unrest) for the long-term assessments. The subjectivity of this choice is herein dealt with expert elicitation.

\section{Result 1: expert elicitations}

We invited experts to multiple panels. The goal of each panel was to define the input for the model BETEF_CF. At each panel, each expert defined a list of parameters, their relevant thresholds to define the occurrence of anomalies, and their weights indicating the perceived importance of each parameter. The parameters are relative to different nodes of the event tree in Figure 1A. At each panel, the opinion of each expert was weighted by their peers.

Five elicitation sessions were organized, preceded by seminars, analysis of previous elicitation results, and debate, and followed by public discussion, during approximately 5 years covering two sequential projects funded by the Italian Dipartimento della Protezione Civile (INGVDPC 2005,2007). A complete list of the elicited experts can be found in Endnotes and in Selva et al. (2009).

During the five expert meetings, the quantitative definition of monitoring parameters, and their availability in real-time from the monitoring network at CFc, were carefully considered. In addition, for each parameter, the concept of an anomaly's inertia has been developed, which defines how long a given change remains significant for forecasting purposes: for example, if a new fracture opens today, for how many days will this count as an "anomaly" before it is no longer significant?

During the first elicitations (I and II), each expert was free to define both parameters and inertia. After these elicitation sessions, each proposed definition was collectively discussed. After elicitation II, a committee (subset of the group of experts) was put in charge of preparing a list of parameters complete with their operative definition and inertia, based on the first two elicitations proposals and subsequent discussions. This list was collectively reviewed before elicitation III, and adopted from there on. Of course, these definitions are reviewable in future, and indeed few minor changes were discussed and implemented before elicitation IV and V. Note that, according to the operative definition of parameters' inertia, it decreases from node 1 to 3 , consistent with the view that changes are expected to become progressively more rapid when approaching the eruption. This is of course an assumption that reflects the group's view, and it may significantly affect the model's forecasts if only few anomalies, with effective inertia much greater than the defined one, are recorded before an event. This was considered an acceptable assumption.

In each elicitation session, experts were individually elicited in a blind procedure, with the following objectives:

(i) An individual weight $w_{e}$ was anonymously assigned to each expert by the other members of the panel. To do this, each expert voted up to 5 other experts with a weight of 1 or 2 (self-voting was not permitted). This vote was about each expert's understanding of CFc. The expert's weight $w_{e}$ is then computed as the sum of all votes received.

(ii) Each expert identified the monitoring parameters and thresholds that are relevant at each node of the event tree. One expert could also select a parameter, without defining thresholds, if he/she judged this out of his/her own expertise. In addition, at nodes 2 and 3 (magmatic unrest and eruption, respectively), for each parameter, the expert selected a weight $w_{i}^{p}$ (equal to 1 or 2 , where $i$ runs over all parameters) to indicate how informative an anomaly of that parameter is at that node. Each parameter received a score $s$ that is the sum of the weights of the experts $w_{e}$ that indicated that parameter, as computed in step (i). Two score thresholds $\left(s_{M}\right.$ and $s_{m}$ ) were defined after each elicitation session in order to classify the parameters according to high, intermediate and low score. The parameters with high score $\left(s \geq s_{M}\right)$ were selected, whereas the parameters with intermediate score $\left(s_{M}>s>s_{m}\right)$ were still selected, but assigning them a probability of acceptance $p_{a}$ equal to $\frac{s-s_{m}}{s_{M}-s_{m}}$. The parameters with low score $\left(s \leq s_{m}\right)$ were rejected.

(iii) Thresholds values and weight $w_{i}^{p}$ for each parameter were identified from the estimates provided by the experts through a weighted procedure, with weights $w_{e}$. Lower and upper thresholds were selected as the 50-th percentile of the corresponding distribution. The weight of each parameter for forecasting purposes $\left(w_{i}\right.$ in Figure 1) is assigned as the product of the 50 -th percentile of the $w_{i}^{p}$ distribution multiplied by the probability of acceptance $p_{a}$. 
The results of each elicitation session are reported in Tables 1, 2 and 3 for seismologic, geodetic, and geochemical parameters, respectively. Note that parameters are of two types: fuzzy or boolean. For fuzzy parameters, two thresholds are reported, between which measures progressively evolve from "normal" to "anomalous". In particular, they should be interpreted as in Figure 1B. For example, considering the results of Elicitation V, the number of VT per day $(\mathrm{M}>0.8)$ is considered surely anomalous if greater than 15, possibly anomalous if between 5 and 15, and not anomalous if less than 5. Boolean parameters, reported as YES/NO, represents single observations which alone represent anomaly.

The tables illustrate the progressive convergence of the expert group decisions from highly scattered initial views toward a shared and stable group opinion. The results of subsequent elicitation sessions also show convergence of opinions towards a few stable parameters at each node (Figure 2). Some initial inconsistent definitions of parameters and thresholds were removed through time (e.g., Presence of CLVD, since the present resources at CFc do not allow its real-time assessment). Through the years we observed a progressively more willingness of single experts to openly illustrate the limits as well as the success of their models, and to become more open to modifying previously preferred quantifications in favor of others that emerged collectively from the expert group decision process (e.g., minimum magnitudes, thermal anomalies, seismic event counting).

In Table 4, we report the results of the last elicitation. Noteworthy, the trends evident in the table do not reflect any choice of one single expert or subsets of experts, rather, emerge as an intrinsic group decision. It is therefore remarkable that the elicitation process produced a clear and consistent picture of the expected dynamics that might lead to a possible eruption at CFc. An example can be seen by inspecting the seismic parameters at the three nodes. The "Unrest" node turns out to be sensitive simply to the occurrence of earthquakes; at the "Magmatic" node, depth of hypocenters and waveforms become relevant; finally, acceleration of seismic activity is believed to be critical at "Eruption" node. Similar consistent trends also emerge from the parameters referring to geodetic and geochemical observations, overall providing a scientifically plausible and sound picture.

It is also worth noting that the relevance of fuzzy parameters progressively decreases, when moving from node 1 to 3 , while the relevance of Boolean parameters increases. This reflects (i) the decrease in confidence of experts (there is previous instrumental experience of unrest episodes at CFc, while that experience is missing for pre-eruptive phases), and (ii) the global experience suggesting that an eruption at a long-dormant volcano is usually preceded by macroscopic (easily visible) escalation of phenomena.

In order to check the stability of the results and the possible existence of systematic divergence of opinions between high-weight and low-weight (or zero-weight) experts, the entire procedure was repeated by assigning to each elicited expert the same weight $\left(w_{e}=1\right)$. The results show that the individual-weighting and equal-weighting produce similar probability distributions, but that individual weighting yielded narrower distributions or more unanimity than equal weighting, especially around parameters judged to be critical. In other words, individualweighting results are less dispersed than equal weighting results, and hence provide more informative distributions, even though 50th percentile values are similar. For sake of example, in Figure 3, we report the comparison between the individual-weighted and equal-weighted results for node 1 , in selecting the parameters (upper panel) and in assessing lower thresholds (bottom panel). Analytical results for all nodes and all parameters are available at Selva et al. (2009).

\section{Result 2: BETEF_CF settings}

The BETEF_CF code yields long- and short-term eruption forecasting in the form of a probability distributions of expected frequencies of each node's event ("unrest per month" for node 1, "magmatic unrest" given unrest for node 2, "eruption" given magmatic unrest for node 3), see Figure 1A. The parameters of each distribution are set through a Bayesian inference according to the logic described in Figure 1, panels B and C, and in the text. Here, we report in details how the elicitation results, together with other relevant models/past data, are used to parameterize BETEF_CF at each node.

\section{Node 1: defining background state and unrest phase at CFC}

Node 1 of the Event Tree considers whether there is either (i) unrest, or (ii) no unrest, in the time interval $\left(t_{0}, t_{0}+\tau\right)$, where $t_{0}$ is the present time, and $\tau$ is the time window considered ( 1 month in this application). The definitions of background and unrest are necessarily subjective, since they have to reflect the specific aim of the forecast. Slow secular subsidence over preceding centuries was interrupted by caldera floor uplift beginning about 60 years ago. However, classifying all of the past 60 years as "unrest" is useless for short-term forecast and decision makers. Instead, unrest is pragmatically defined as a state of the volcano that forces us to face the question at node 2: is what is being observed due to magma movements? The corresponding definition of background state is therefore that of a "normal" state in the frame of the present long-lasting unrest at Campi Flegrei.

In this respect BETEF_CF code requires as input a list of monitoring parameters and their thresholds that identify 
Table 1 Elicitation results for seismological parameters

\begin{tabular}{|c|c|c|c|c|c|c|c|}
\hline Parameter & inertia & units & ELICIT. I & ELICIT. II & ELICIT. III & $\begin{array}{l}\text { ELICIT. IV } \\
\text { (on line) }\end{array}$ & $\begin{array}{l}\text { ELICIT. V } \\
\text { (on line) }\end{array}$ \\
\hline \multicolumn{8}{|l|}{ Node 1} \\
\hline \# seismic events & $(*)$ & ev/day & $>1-85$ & - & - & $>10-20$ & - \\
\hline$\# \bigvee \mathrm{VT}(\mathrm{M}>0.8)$ & $(*)$ & ev/day & - & $>2-15^{[\mathrm{mag}]}$ & $>15-85^{[\operatorname{mag} 3]}$ & $>2-5^{[\text {mag } 13]}$ & $>5-15$ \\
\hline Largest Magnitude & last month & - & $>1.7-3.3$ & $>2-3^{[c o]}$ & $>2-3$ & $>3-4^{[p 20]}$ & - \\
\hline$\#$ LP & $(*)$ & ev/month & $>0$ & $>2-10$ & $>1-10$ & canceled & canceled \\
\hline \# LP/NLP/ULP & $(*)$ & ev/month & - & - & - & $>1-10^{[p 20]}$ & $>2-10$ \\
\hline \multicolumn{8}{|l|}{ Node 2} \\
\hline \# seismic events & $(*)$ & ev/day & $>1-100(1)$ & - & $>20-110(1)$ & - & - \\
\hline$\# \bigvee T(M>1.3)$ & $(*)$ & ev/day & - & $>15-70(1)^{[m a g]}$ & - & $>20(1)^{[p 27]}$ & - \\
\hline \# deep VT (> 3.5 km, M > 0.8) & $(*)$ & ev/day & - & - & - & $>1-4(1)^{[\operatorname{mag} 3]}$ & $>2-20(1)^{[p 90]}$ \\
\hline Largest Magnitude & last month & - & $>2.6-4.0(1)$ & $>3.6-4.5(1)$ & $>3.3-4.3(1)$ & $>4(1)^{[p 20]}$ & - \\
\hline$\#$ LP & $(*)$ & ev/month & $>0-10(1)$ & $>1-30(1)$ & $>20-40(1)$ & - & - \\
\hline \# deep LP (> 2.0 km) & $(*)$ & ev/month & - & - & $>1-7(2)^{[\operatorname{dep} 30]}$ & $>2-8(2)^{[\operatorname{dep} 35]}$ & $>3-20(1)^{[p 50]}$ \\
\hline$\# \bigvee V L P / U L P$ & $(*)$ & ev/month & - & $>0(2)^{[u / p]}$ & $>2-6(2)$ & $>1-2(2)^{[p 07]}$ & $>1-5(1)$ \\
\hline \# deep VLP/ULP (> 3.5 km) & $(*)$ & ev/month & - & - & - & $>1-5(2)^{[p 73]}$ & - \\
\hline Presence of tremor & last month & - & - & - & - & YES/NO (1) $)^{[r e d]}$ & YES/NO (1) \\
\hline $\begin{array}{l}\text { Presence of deep tremor } \\
(>3.5 \mathrm{~km})\end{array}$ & last month & - & - & - & - & YES/NO (1) & YES/NO (1) \\
\hline Maximum depth (> 6 events) & - & $\mathrm{km}$ & $>6(1)^{[\min ]}$ & $>4-8(1)^{[\min ]}$ & $>4-6(1)$ & canceled & canceled \\
\hline Presence of CLVD & - & - & YES/NO (1) & YES/NO (1) & canceled & canceled & canceled \\
\hline
\end{tabular}

\section{Node 3}

\begin{tabular}{|c|c|c|c|c|c|c|c|}
\hline \# seismic events & $(*)$ & ev/day & $>50-240(1)$ & - & - & - & - \\
\hline$\# \bigvee T(M>1.3)$ & $(*)$ & ev/day & - & - & - & $>50-200(2)^{[p 87]}$ & - \\
\hline $\begin{array}{l}\text { Acceleration in \# seismic } \\
\text { events }\end{array}$ & last week & - & YES/NO (1) & YES/NO (2) & YES/NO (1) & YES/NO (1) & YES/NO (1) \\
\hline Acceleration in RSAM & last week & - & - & - & - & YES/NO (1) ${ }^{[p 93]}$ & $\mathrm{YES} / \mathrm{NO}(1)^{[p 70]}$ \\
\hline Presence of tremor & last month & - & $\mathrm{YES} / \mathrm{NO}(1)$ & YES/NO (1) & YES/NO (2) & YES/NO (2) $)^{[p 53]}$ & YES/NO (1) \\
\hline Upward migration & - & - & YES/NO (1) & canceled & canceled & canceled & canceled \\
\hline $\begin{array}{l}\text { Hypocenter dispersion (depth } \\
\text { range) }\end{array}$ & last week & $\mathrm{km}$ & - & YES/NO (1) [qual] & $\mathrm{YES} / \mathrm{NO}(1)^{[q u a l]}$ & $>1-3(1)^{[p 53]}$ & $>1-3(1)^{[p 30]}$ \\
\hline$\left(10^{\text {th }}-90^{\text {th }}\right.$ perc. $)$ & & & & & & & \\
\hline
\end{tabular}

\section{NOTES:}

$(*)$ : number of observed events divided by the number of days from the observation. This choice makes the inertia proportional to the registered number of events (and the total energy emitted), that is, the higher the number of events, the longer the inertia.

[ $\boldsymbol{c o}$ ]: parameter added for coherence among nodes.

[ $\boldsymbol{d e p} \boldsymbol{x} \boldsymbol{x}$ ]: the threshold distinguishing between deep and shallow events is $\mathrm{x} . \mathrm{X} \mathrm{Km}$.

[ $\boldsymbol{m a g}$ ]: completeness magnitude not yet defined.

[ mag13]: completeness magnitude set to 1.3.

[ mag3]: completeness magnitude set to 3.0 .

[ $\boldsymbol{m i n}]$ : minimum number of events not yet defined.

[pnn]: parameter partially accepted, i.e., with probability of acceptance $\left(\boldsymbol{p}_{\boldsymbol{\alpha}}\right)$ equal to $\mathbf{0 . n n}$.

[ qual]: the parameter is qualitatively defined (YES/NO).

[red]: redundant parameter.

[ulp]: ULP not yet included.

Legend: The analytic elicitation results for seismological parameters are reported. For fuzzy parameters, lower (T1) and upper (T2) threshold are reported, with the symbolism "T1-T2 (weight)". For Boolean parameters YES/NO is reported, with the symbolism "YES/NO (weight)". At node 1, weights are not present, since they are not required by the model. The symbol \# stands for "The number of", while other symbols are defined in section List of Abbreviation. Further specifications, when necessary, are reported in NOTES. 
Table 2 Elicitation results for geodesy parameters

\begin{tabular}{|c|c|c|c|c|c|c|c|}
\hline Parameter & inertia & units & ELICIT. I & ELICIT. II & ELICIT. III & $\begin{array}{l}\text { ELICIT. IV } \\
\text { (on line) }\end{array}$ & $\begin{array}{l}\text { ELICIT. V } \\
\text { (on line) }\end{array}$ \\
\hline \multicolumn{8}{|l|}{ Node 1} \\
\hline Uplift & cum. last 3 months & $\mathrm{cm}$ & $>1-20^{[c h]}$ & $>2-5^{[c h]}$ & $>2-5^{[c h]}$ & $>2-5^{[c h]}$ & $>2-6$ \\
\hline Uplift rate & last 3 months & $\mathrm{cm} / \mathrm{month}$ & $>1-50$ & $>2-10$ & $>2-7$ & $>1.2-2$ & $>0.7-1.3$ \\
\hline New fractures & last 3 months & - & - & - & - & - & YES/NO (1) ${ }^{[p 70]}$ \\
\hline $\begin{array}{l}\text { Positive gravimetric } \\
\text { change }\end{array}$ & last 3 months & $\mu \mathrm{Gal}$ & $>36-180$ & $>40-50$ & - & - & - \\
\hline $\begin{array}{l}\text { Absolute gravimetric } \\
\text { change }\end{array}$ & last 3 months & $\mu \mathrm{Gal}$ & - & - & $>20-40$ & $>30-50$ & - \\
\hline
\end{tabular}

\section{Node 2}

\begin{tabular}{lccccccc}
\hline Uplift & cum. last 3 months & $\mathrm{cm}$ & $>1-100(1)^{[\mathrm{ch}]}$ & - & - & - & $>5-15(1)$ \\
\hline Uplift rate & last 3 months & $\mathrm{cm} /$ month & - & $>10-30$ & $>35-135(1)$ & $>5-20(2)^{[p 33]}$ & - \\
\hline Macroscopic variation on & last 3 months & - & - & YES/NO (1) & YES/NO (1) & YES/NO (1) & YES/NO (1)
\end{tabular}

the

deformation pattern (tens of $\mathrm{m}$ )

\begin{tabular}{llllll}
\hline New fractures & last 3 months & - & - & - & - \\
\hline $\begin{array}{l}\text { Absolute gravimetric } \\
\text { change }\end{array}$ & last 3 months & $\mu \mathrm{Gal}$ & - & $>20-100(1)$ & - \\
\hline $\begin{array}{l}\text { Positive gravimetric } \\
\text { change }\end{array}$ & last 3 months & $\mu \mathrm{Gal}$ & $>100-270(1)$ & - & - \\
\hline
\end{tabular}

\section{Node 3}

\begin{tabular}{lcccccc}
\hline Uplift & cum. last 3 months & $\mathrm{cm}$ & $>50-100(1)^{[\mathrm{ch}]}$ & - & - & - \\
\hline Uplift rate & last 3 months & $\mathrm{cm} /$ day & - & $>5-10$ & $>8-45$ & - \\
\hline Acceleration in uplift & - & - & YES/NO (1) & YES/NO (2) & canceled & canceled \\
\hline Macroscopic variation on & last week & - & YES/NO (1) & - & - & canceled
\end{tabular}

the

deformation pattern (tens of $\mathrm{m}$ )

\begin{tabular}{|c|c|c|c|c|c|c|c|}
\hline $\begin{array}{l}\text { Migration of incremental } \\
\text { maximum (m) }\end{array}$ & last week & - & - & - & - & - & YES/NO (1) $)^{[p 70]}$ \\
\hline New fractures & last 3 months & - & YES/NO (1) & YES/NO (1) & YES/NO (1) & YES/NO (1) & YES/NO (1) $)^{[p 40}$ \\
\hline
\end{tabular}

\section{NOTES:}

[ $\boldsymbol{c h}$ ]: from change of sign of deformation.

[ $\boldsymbol{p n n}$ ]: parameter partially accepted, i.e., with probability of acceptance $\left(\boldsymbol{p}_{\boldsymbol{\alpha}}\right)$ equal to $\mathbf{0 . n n}$.

Legend: The analytic elicitation results for geodesy parameters are reported. The same symbols of Table 1 are used.

anomalies with respect to the background activity, i.e., a phase of unrest. The output of the expert elicitation sessions for node 1 is reported in Table 4 . When at least one anomaly is detected by BETEF_CF, the probability of unrest is set to the degree of unrest, that is, the largest degree of anomaly detected all over the parameters (see Marzocchi et al. 2008 and Figure 1B).

When no anomalies are detected, the BETEF_CF estimates the long-term probability of unrest. To do so, we set the prior information to a uniform distribution (maximum ignorance, i.e., $\Theta_{1}=0.5$ and $\Lambda_{1}=1$, see Figure 1B and Marzocchi et al. 2008). In order to define the likelihood distribution in the Bayesian inference scheme, we divide the period 1981-2009 into subsequent nonoverlapping time windows of length $\tau=1$ month. Then, we count the number of months that started with no unrest up to that time window (number of 'trials') and the number of times that a new unrest episode starts within the time window, the latter corresponding to the number of observed unrest episodes up to then (number of 'successes') (Marzocchi et al. 2008; Sandri et al. 2009). In this count, we also include partial unrest episodes with a fractional value equal to the measured Degree of Unrest $\eta$ (see Marzocchi et al. 2008, ESM). With these parameters, 
Table 3 results for geochemistry and thermal parameters

\begin{tabular}{|c|c|c|c|c|c|c|c|}
\hline Parameter & inertia & units & ELICIT.I & ELICIT. II & ELICIT. III & $\begin{array}{l}\text { ELICIT. IV } \\
\text { (on line) }\end{array}$ & $\begin{array}{l}\text { ELICIT. V } \\
\text { (on line) }\end{array}$ \\
\hline \multicolumn{8}{|l|}{ Node 1} \\
\hline $\begin{array}{l}\text { Degassing structure extension } \\
\text { or increase in flux }\end{array}$ & last month & - & $>1.8-2.2^{[p g f]}$ & - & YES/NO & - & $\mathrm{YES} / \mathrm{NO}^{[p 70]}$ \\
\hline $\begin{array}{l}\text { Change in composition of } \\
\text { gases }\end{array}$ & last month & - & YES/NO & $\mathrm{YES} / \mathrm{NO}^{[\mathrm{co}]}$ & YES/NO & - & - \\
\hline $\mathrm{CO}_{2} / \mathrm{H}_{2} \mathrm{O}$ ratio & last month & - & $>0.20$ & $>0.20-0.25$ & - & cancelled & cancelled \\
\hline $\begin{array}{l}\text { Presence of acid gases }(\mathrm{HF}, \mathrm{HCl}, \\
\left.\mathrm{SO}_{2}\right)\end{array}$ & last week & - & - & - & - & $\mathrm{YES} / \mathrm{NO}^{[p 27]}$ & $\mathrm{YES} / \mathrm{NO}^{[p 10]}$ \\
\hline Thermal anomaly & - & - & - & - & YES/NO & cancelled & cancelled \\
\hline $\begin{array}{l}\text { Change in temperature of } \\
\text { gases }\end{array}$ & - & ${ }^{\circ} \mathrm{C}$ & $>10-15$ & $>10-15^{[\mathrm{co}]}$ & - & cancelled & cancelled \\
\hline $\begin{array}{l}\text { Change in thermal radiation of } \\
\text { fractures }\end{array}$ & - & - & YES/NO & $\mathrm{YES} / \mathrm{NO}^{[\mathrm{co}]}$ & - & cancelled & cancelled \\
\hline $\begin{array}{l}\text { Temperature at fumarole "Pis- } \\
\text { ciarelli" }\end{array}$ & last month & ${ }^{\circ} \mathrm{C}$ & - & - & - & - & $>100-110^{[p 40}$ \\
\hline \multicolumn{8}{|l|}{ Node 2} \\
\hline $\begin{array}{l}\text { Presence of acid gases }(\mathrm{HF}, \mathrm{HCl} \text {, } \\
\left.\mathrm{SO}_{2}\right)\end{array}$ & last week & - & YES/NO (1) & YES/NO (2) & YES/NO (2) & $\mathrm{YES} / \mathrm{NO}(2)^{[p 47]}$ & YES/NO (1) \\
\hline $\begin{array}{l}\text { Variation in magmatic compo- } \\
\text { nent }\end{array}$ & last month & - & - & - & - & $\mathrm{YES} / \mathrm{NO}(1)^{[p 47]}$ & $\mathrm{YES} / \mathrm{NO}(1)^{[p 10}$ \\
\hline $\begin{array}{l}\text { Change in temperature of } \\
\text { gases }\end{array}$ & last month & ${ }^{\circ} \mathrm{C}$ & $>20-30(1)$ & $>5-20(2)$ & - & - & - \\
\hline \multicolumn{8}{|l|}{ Node 3} \\
\hline $\begin{array}{l}\text { Degassing structure extension } \\
\text { or increase in flux }\end{array}$ & last week & - & $>5-50(1)[p g f]$ & - & - & - & - \\
\hline $\begin{array}{l}\text { Change in temperature of } \\
\text { gases }\end{array}$ & last week & ${ }^{\circ} \mathrm{C}$ & $>20-50(1)$ & - & - & - & - \\
\hline $\begin{array}{l}\text { Presence of acid gases }(\mathrm{HF}, \mathrm{HCl}, \\
\left.\mathrm{SO}_{2}\right)\end{array}$ & last week & - & YES/NO (1) & YES/NO (1) & YES/NO (2) & YES/NO (1) & YES/NO (1) \\
\hline Phreatic activity & last week & - & - & - & - & $\mathrm{YES} / \mathrm{NO}(1)^{[p 47]}$ & YES/NO (1) \\
\hline
\end{tabular}

NOTES:

[ $\boldsymbol{c o}$ ]: parameter added for coherence among nodes.

$[\boldsymbol{p g} f]$ : percent gas flux change.

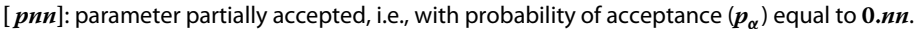

Legend: The analytic elicitation results for geochemistry and thermal parameters are reported. The same symbols of Table 1 are used.

the probability distribution relative to the occurrence of an unrest (node 1 ) in the next $\tau$ is completely defined for each of the time windows, and it changes with time as new information is acquired in a sort of learning procedure. At the end of the examined period (Jan. 1st 1981 - Dec. 31st 2009), the number of trials at node 1 was $n_{1}=306$, while the successes were $y_{1}=7.4$. The posterior distribution is therefore a Beta distribution with parameters $\alpha=8.4$ and $\beta=299.6$.

\section{Node 2: magmatic unrest}

In case of unrest, we must focus on quantifying whether the unrest is due (i) to new magma, or (ii) to other causes (e.g., hydrothermal, tectonics, etc.). A hydrothermal eruption could threaten areas within a few kilometers of a vent. In CFc this is serious and deserves attention in future work. Here, though, we focus only on magmatic unrest that can lead to magmatic eruptions. The distinction between magmatic and non-magmatic unrest involves some subjective considerations because the presence of magma in a volcanic system is obvious. Pragmatically, we identify magmatic unrest when magma is in motion (e.g., significant reactivation of convection in a magma chamber, of dyke intrusion).

If BETEF_CF detects unrest at node 1 , the shortterm analysis is based on the anomalies recorded to the 


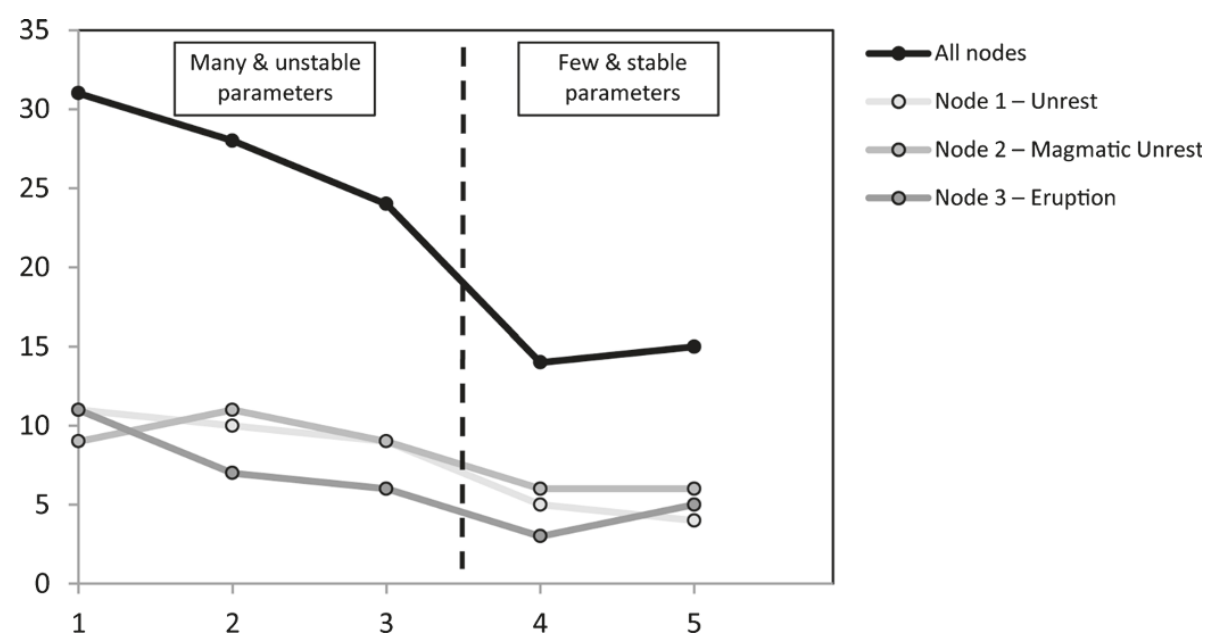

Figure 2 Convergence in the number of selected parameters through elicitation sessions. The number of selected parameters (here we only show those with $p_{\alpha}=1$ ) decreases significantly through elicitation sessions, showing the convergence process of experts. The vertical dashed line highlights the significant change occurred after elicitation III, when the number of the selected parameters fell. The results of the last elicitation do not differ substantially from those of the previous session, and results show that both the number (in figure) and the definition of parameters (in Tables 1, 2 and 3) are stable. Thus, those results represent the outcome of the experiment. More details can be found in the text.

parameters relative to node 2 . The output of the expert elicitation sessions for node 2 is again reported in Table 4. These anomalies are then transformed into probability distributions.

When BETEF_CF does not detect unrest at node 1 , the probabilistic analysis at node 2 is based on the long-term assessment. In this case, the prior information is given by a uniform distribution $\left(\Theta_{2}=0.5\right.$ and $\Lambda_{2}=1$, see Figure $1 \mathrm{~B}$ and Marzocchi et al. 2008) since specific knowledge on the relative frequency of occurrence of magmatic unrest episodes, with respect to other unrest types, is not available. Similarly, no past data are used since the magmatic vs. hydrothermal origin of the unrest episodes since 1981 is still debated (e.g., Bonafede 1991; De Siena 2010, and references therein). For this reason, we have chosen not to consider past data at node 2 . The posterior distribution is therefore a Beta distribution with parameters $\alpha=$ $\beta=1$.

\section{Node 3: magmatic eruption}

In case of unrest with a magmatic origin, at node 3 we consider whether (i) the magma will reach the surface (i.e., it will erupt), or (ii) it will not, in the time interval $\left(t_{0}, t_{0}+\tau\right)$.

If BETEF_CF detects unrest at node 1, the short-term analysis is based on the anomalies recorded to the parameters relative to node 3 . The output of the expert elicitation sessions for node 3 is again reported in Table 4. These anomalies are then transformed into probability distributions.

When BETEF_CF does not detect unrest at node 1 , the probabilistic analysis at node 3 is based on the long-term assessment. In this case, prior information was derived from the worldwide database of unrest at calderas similar to CFc (Newhall and Dzurisin 1988). Such database shows a frequency of unrest culminating in an eruption at silicic calderas (with unrest in the past 100 years and repose of more than 100 years, as in CFc case) of about 1 out of 6 . Here, allowing for our ignorance on the nature of unrest (see above for Node 2), we estimate that 50\% of unrest might be magmatic and so the prior best guess at Node $3\left(\Theta_{3}\right.$, see Figure $1 \mathrm{~B}$ and Marzocchi et al. 2008) is set at $(1 / 6) / 0.5=0.33$. For this prior model, we also set the maximum allowed epistemic uncertainty (the equivalent number of data $\Lambda_{3}=1$; see Figure 1B and Marzocchi et al. 2008). Note that an informative (even if weak) prior model is introduced only at node 3 , and not at the previous nodes. This reflects the effective lack of credible models about volcanic unrest episodes. Indeed, future improvement on this issue will allow us to use more informative prior distributions at the different nodes of BET EF. At node 3 , past data are represented by the number of eruptions ('successes') compared to the number of observed magmatic unrest episodes (node 2) which we do not know (see above). Thus, allowing again for an expectancy of $50 \%$ of magmatic unrest out of all unrest episodes, the background assessment at node 3 of BETEF_CF accounts for no observed eruption $\left(y_{3}=0\right)$ out of $n_{3}=0.5 * y_{1}=3.7$ supposedly magmatic unrest episodes since 1981 . With these parameters, the background probability distribution relative to node 3 (eruption) is completely defined by a beta distribution with parameters $\alpha=0.67$ and $\beta=5.03$. 
Table 4 results of the elicitation $\mathrm{V}$

\begin{tabular}{|c|c|c|c|c|}
\hline & inertia & units & threshold & weight \\
\hline \multicolumn{5}{|l|}{ Node 1} \\
\hline 1) $\# \vee T(M>0.8)$ & $(*)$ & ev/day & $>5-15$ & - \\
\hline 2) \# LP/NLP/ULP & $(*)$ & ev/month & $>2-10$ & - \\
\hline 3) Uplift & cum. last 3 months & $\mathrm{cm}$ & $>2-6$ & - \\
\hline 4) Uplift rate & last 3 months & $\mathrm{cm} / \mathrm{month}$ & $>0.7-1.3$ & - \\
\hline 5) New fractures & last 3 months & - & YES/NO & - \\
\hline 6) Degassing structure extension or increase in flux & last month & - & YES/NO & - \\
\hline 7) Presence of acid gases $\left(\mathrm{HF}, \mathrm{HCl}, \mathrm{SO}_{2}\right)$ & last week & - & YES/NO & - \\
\hline 8) Temperature at fumarole "Pisciarelli" & last month & ${ }^{\circ} \mathrm{C}$ & $>100-110$ & - \\
\hline \multicolumn{5}{|l|}{ Node 2} \\
\hline 1) \# deep VT (> $3.5 \mathrm{~km}, \mathrm{M}>0.8)$ & $(*)$ & ev/day & $>2-20$ & 0.90 \\
\hline 2) \# deep LP (> $2.0 \mathrm{~km})$ & $(*)$ & ev/month & $>3-20$ & 0.50 \\
\hline 3) \# VLP/ULP & $(*)$ & ev/month & $>1-5$ & 1 \\
\hline 4) Presence of tremor & last month & - & YES/NO & 1 \\
\hline 5) Presence of deep tremor (> $3.5 \mathrm{~km}$ ) & last month & - & YES/NO & 1 \\
\hline 6) Uplift & cum. last 3 months & $\mathrm{cm}$ & $>5-15$ & 1 \\
\hline 7) New fractures & last 3 months & - & YES/NO & 0.20 \\
\hline $\begin{array}{l}\text { 8) Macroscopic variation on the } \\
\text { deformation pattern (tens of m) }\end{array}$ & last 3 months & - & YES/NO & 1 \\
\hline 9) Presence of acid gases $\left(\mathrm{HF}, \mathrm{HCl}, \mathrm{SO}_{2}\right)$ & last week & - & YES/NO & 1 \\
\hline 10) Variation in magmatic component & last month & - & YES/NO & 0.10 \\
\hline \multicolumn{5}{|l|}{ Node 3} \\
\hline 1) Acceleration in \# seismic events & last week & - & YES/NO & 1 \\
\hline 2) Acceleration in RSAM & last week & - & YES/NO & 0.70 \\
\hline 3) Presence of tremor & last month & - & $\mathrm{YES} / \mathrm{NO}$ & 1 \\
\hline 4) Hypocenter dispersion (depth range) $\left(10^{\text {th }}-90^{\text {th }}\right.$ perc.) & last week & $\mathrm{km}$ & $>1-3$ & 0.30 \\
\hline $\begin{array}{l}\text { 5) Macroscopic variation on the } \\
\text { deformation pattern (tens of m) }\end{array}$ & last week & - & YES/NO & 1 \\
\hline 6) Migration of incremental maximum (m) & last week & - & YES/NO & 0.70 \\
\hline 7) New fractures & last 3 months & - & YES/NO & 0.40 \\
\hline 8) Presence of acid gases $\left(\mathrm{HF}, \mathrm{HCl}, \mathrm{SO}_{2}\right)$ & last week & - & YES/NO & 1 \\
\hline 9) Phreatic activity & last week & - & YES/NO & 1 \\
\hline
\end{tabular}

NOTES:

(*): number of observed events divided by the number of days from the observation. This choice makes the inertia proportional to the registered number of events (and the total energy emitted), that is, the higher the number of events, the longer the inertia.

Legend: The results of the elicitation $V$ are here reported. The same symbols of Table 1 are used.

\section{Result 3: Current and retrospective application}

The main result of this paper is the set up of the BETEF_CF model, as reported in Tables 4 and 5. This model, based on the group opinion of experts, is able to analyze the continuous flux of information coming from the CFc monitoring system, estimating the monthly probability of eruption in almost real-time through Eq. 1.

If no anomalies are detected, BETEF_CF provides the background monthly probability of eruption at CFc
(Figure 1C). As shown above, this background analysis is based on theoretical models and data since 1981 and it accounts only for the long-term ongoing uplift dynamics of CFc. The long-term (background) expected (mean) eruption probability, updated to the 31st December 2009, in the following 1 month is $1.6 \cdot 10^{-3}$, with a $80 \%$ confidence interval $\left[4 \cdot 10^{-5}-4 \cdot 10^{-3}\right]$ defined by the 10 -th and 90-th percentiles of the distribution. Such confidence interval reflects the epistemic uncertainty on the expected 

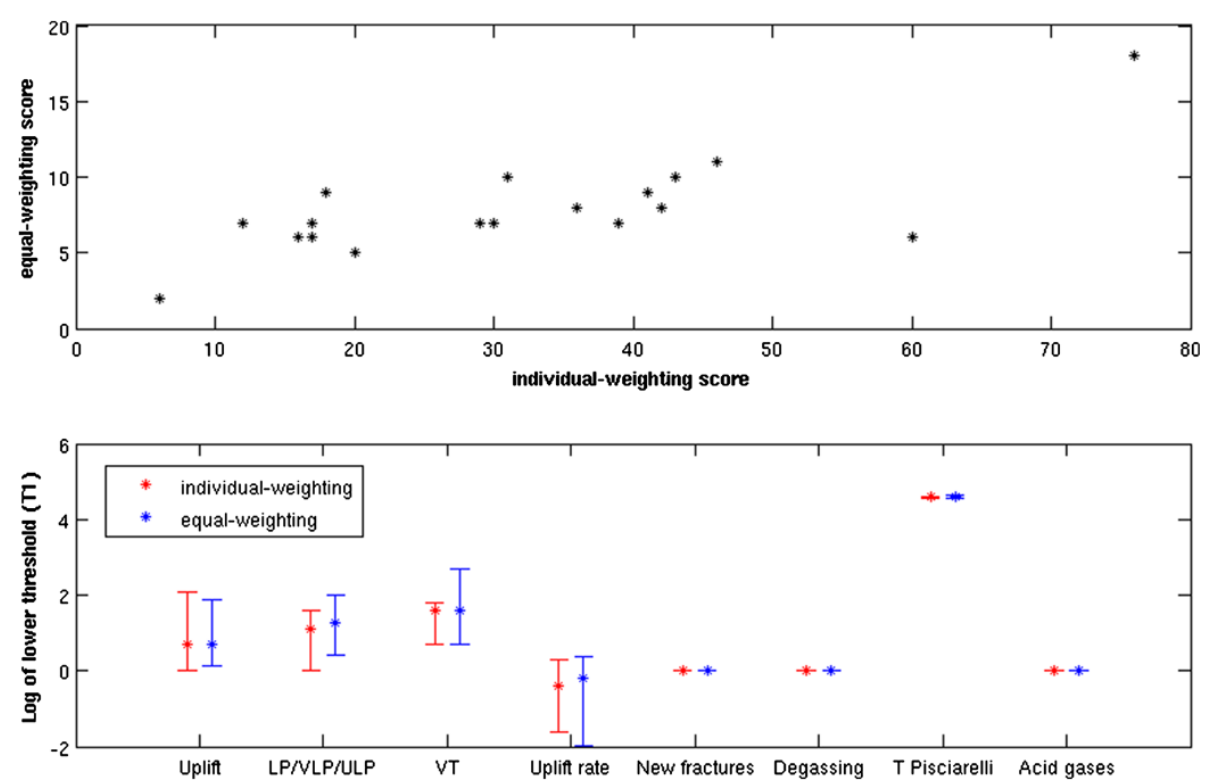

Figure 3 Sensitivity test on expert's weighting scheme. Top panel, comparison of the parameter's scores $s$, as assessed through individual-weighted (assessed from expert's weights $w_{e}$ ) and equal-weighted (assessed imposing $w_{e}=1$ ) procedures, relative to node 1 of elicitation $V$. The results from the two methods appear well correlated, showing that the selection of parameters $\left(s>s_{m}\right)$ is rather stable with respect to $w_{e}$. In the bottom panel, we report the statistics on the lower threshold for selected parameters at node 1 of elicitation $V$, evaluated in the individual-weighted (red) and equal-weighted (blue) procedures. Bars indicate confidence interval (80\%) and stars represent the median. The results show that the two procedures results in equivalent medians, but the equal-unweighted procedure generally provides larger confidence intervals. Equivalent results for all nodes and parameters can be found in Selva et al. (2009).

probability estimate, as it propagates through nodes 1 to 3. Noteworthy, this estimated background monthly probability of eruption is of the same order of magnitude of the better-known Mt. Vesuvius, as estimated through an analogous procedure in Marzocchi et al. (2008). This implies that the hazard exposure of Naples due to CFc, even in quiet periods, is higher than for Vesuvius, given that expected eruption sizes are comparable (Marzocchi et al. 2004; Orsi et al. 2009), but the city center is closer to the eruptive vents of CFc, and more directly downwind (Selva et al. 2010, 2012).

Whenever anomalies are detected, monitoring measures start being informative about the short-term

Table 5 Background settings of BETEF_CF

\begin{tabular}{lll}
\hline Node & Prior parameters & $\begin{array}{l}\text { Likelihood } \\
\text { parameters }\end{array}$ \\
\hline Node 1: UNREST & No info- uniform & $n_{1}=306$ \\
& $\left(\Theta_{1}=0.5 \& \Lambda_{1}=1\right)$ & $y_{1}=7.4$ \\
Node 2: MAGMATIC-UNREST & No info-uniform & $n_{2}=0$ \\
& $\left(\Theta_{2}=0.5 \& \Lambda_{2}=1\right)$ & $y_{2}=0$ \\
Node 3: MAGMATIC-UNREST & $\left(\Theta_{3}=0.33 \& \Lambda_{3}=1\right)$ & $n_{3}=3.7$ \\
& $\Lambda_{3}=1$ & $y_{3}=0$ \\
\hline
\end{tabular}

Legend: Background settings of BETEF_CF, updated to the end of 2009. See text for more details. behavior of the system, and the forecasts provided by BETEF_CF account for their fast evolution in near realtime. Such a strategy has been shown to provide results in agreement with more classical processes of experts' decision during crises (e.g., Sandri et al. 2009; Lindsay et al. 2010), usually involving the set-up of a team receiving real-time data and discussing them collectively to achieve consensus. BETEF_CF can speed delivery of analysis to decision-makers.

In Figure 4 we show a retrospective application of the BETEF_CF code to track the unrest evolution at CFc in the period 1981-2010. At the beginning of this time interval, the monitoring capability was not comparable to the present one; this inhomogeneity poses some constraints to the resolution of the probability variations through time. Nonetheless, this example highlights the main features of the BETEF_CF code applied to a real case. In Figure 4 we also report the eruption probability distribution at three different times; each distribution displays the estimated probability (central value) and the associated epistemic uncertainty (dispersion around the central value) (Marzocchi et al. 2008).

\section{Conclusions}

The BETEF_CF represents a valuable tool that can be used in real-time during an episode of caldera unrest. However, it is not intended to replace advisory groups, 


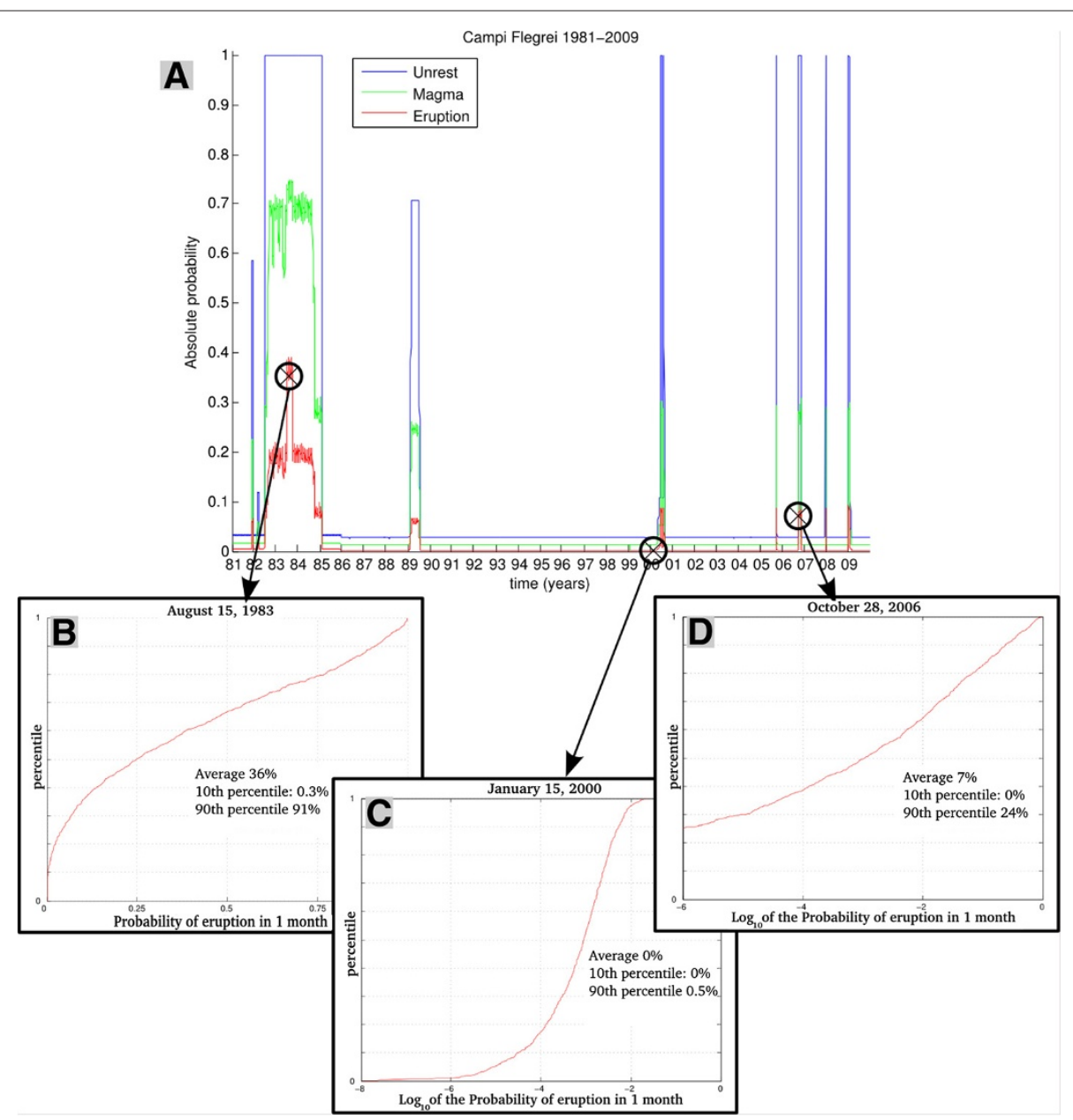

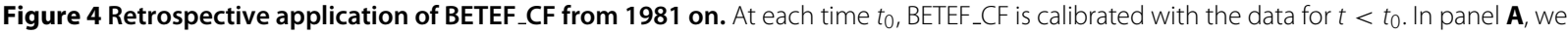
report the average (best estimate) probability of unrest (blue), magmatic unrest (green) and eruption (red) for the following 1 month. In panels B, C and $\mathbf{D}$, at three different time, we report a snapshot of the cumulative distribution (percentiles) of the probability of eruption, highlighting the epistemic uncertainty on the estimated probability. Spikes in the probability values (main figure) represent unrest episodes, during which monthly probabilities are much greater than the background ones. The major unrest period 1982-84 (Barberi et al. 1984), as well as each one of the minor uplift phases that followed, are correctly identified as anomalous. In particular, BETEF_CF shows that starting from mid-1982 the volcano was certainly in an anomalous state (probability $100 \%$ at node 1), the average probability that the unrest was due to active magma movements was about $70 \%$, and the probability of an eruption on a time window of one month was about $20 \%$, with a peak of nearly $40 \%$ in the period June-September 1983 (in October the evacuation took place). Such a high value is in agreement with the perception of some volcanologists at the time (Civetta and Gasparini 2012), even if explicit quantifications of probabilities were not available. In late 1984 the eruption probability returned to lower values around 10\%, and the crisis was definitely over at the beginning of the following year. The so-called mini-uplift phases that punctuated the activity of CFc from year 2000 are similar to each other in terms of probabilities, with the eruption probability always less than 10\%.

expert panels, or other means of evaluation that are commonly set up during major crises; rather, it represents an additional powerful tool that can help by focusing discussion and by saving time in exploring the changing eruption parameter-uncertainty space (Lindsay et al. 2010). Some of the characteristics of BETEF_CF make this procedure unique and highly desirable: i) the estimates from BETEF_CF are quantitative and reproducible, allowing therefore a fully transparent process of scientific evaluation during the crisis; ii) they are not the product of one single expert or restricted to a limited sub-group of experts, but instead represent a decision distilled from a large community, thus giving more robustness to the forecasts; iii) the forecasts are unaffected by temporal, political or sociological demands during the crisis, but are objective since based on new data and previously quantified consensus views; iv) the calibration through expert elicitation can be updated with the most recent and robust scientific results. The expert community decides through a blind process if new results should be included in BETEF_CF, and the weight to assign to them, so that scientific robustness is the only driver of new updates; 
v) BETEF_CF provides a clear aid to volcano scientists during a crisis, represented by the interpretation of observations and provision of forecasts, helping distinguish in a clear and unambiguous way the role of volcanologists from that of decision-makers.

Whilst we report here the specific case of CFc, the approach can be generalized to other volcanoes where little or no pre-eruptive data are available.

\section{Endnotes}

We report a complete list of the participants to all the elicitation sessions, in strict alphabetical order. In parenthesis, we report the elicitation at which single researchers participated. This list can be found also at the elicitations' website (Selva et al. 2009).

1. Belardinelli M.E. (V), University of Bologna, Italy

2. Berrino G. (I,III), Osservatorio Vesuviano, Istituto Nazionale di Geofisica e Vulcanologia, Naples, Italy

3. Bianco F. (I,III,IV,V), Osservatorio Vesuviano, Istituto Nazionale di Geofisica e Vulcanologia, Naples, Italy

4. Bonafede M. (I,II,III,V), University of Bologna, Bologna, Italy

5. Bruno P.P. (I), Osservatorio Vesuviano, Istituto Nazionale di Geofisica e Vulcanologia, Naples, Italy

6. Caliro S. (III,V), Osservatorio Vesuviano, Istituto Nazionale di Geofisica e Vulcanologia, Naples, Italy

7. Chiodini G. (I,II,III,V), Osservatorio Vesuviano, Istituto Nazionale di Geofisica e Vulcanologia, Naples, Italy

8. Civetta L. (I,II,III,IV,V), University of Naples "Federico II", Naples, Italy

9. D’Auria L. (I), Osservatorio Vesuviano, Istituto Nazionale di Geofisica e Vulcanologia, Naples, Italy

10. De Siena L. (III,IV), Osservatorio Vesuviano, Istituto Nazionale di Geofisica e Vulcanologia, Naples, Italy

11. De Vita S. (II), Osservatorio Vesuviano, Istituto Nazionale di Geofisica e Vulcanologia, Naples, Italy

12. Del Pezzo E. (III,IV,V), Osservatorio Vesuviano, Istituto Nazionale di Geofisica e Vulcanologia, Italy

13. Del Gaudio C. (I,II,III), Osservatorio Vesuviano, Istituto Nazionale di Geofisica e Vulcanologia, Naples, Italy

14. Di Vito M.A. (I,II,III,IV), Osservatorio Vesuviano, Istituto Nazionale di Geofisica e Vulcanologia, Italy

15. Festa G. (III,IV,V), University of Naples "Federico II", Naples, Italy

16. Giudicepietro F.(III,IV,V), Osservatorio Vesuviano, Istituto Nazionale di Geofisica e Vulcanologia, Naples, Italy

17. Longo A. (V), Sezione di Pisa, Istituto Nazionale di Geofisica e Vulcanologia, Pisa, Italy
18. Macedonio G. (II,III,IV), Osservatorio Vesuviano, Istituto Nazionale di Geofisica e Vulcanologia, Naples, Italy

19. Martini M. (II), Osservatorio Vesuviano, Istituto Nazionale di Geofisica e Vulcanologia, Naples, Italy

20. Marzocchi W. (I,II,III,IV,V), sezione Roma 1, Istituto Nazionale di Geofisica e Vulcanologia, Rome, Italy

21. Montagna C.P. (III,IV,V), sezione di Pisa, Istituto Nazionale di Geofisica e Vulcanologia, Pisa, Italy

22. Moretti R. (II,III,IV,V), Osservatorio Vesuviano, Istituto Nazionale di Geofisica e Vulcanologia, Naples, Italy, and Second University of Naples, Naples, Italy

23. Neri A. (I), sezione di Pisa, Istituto Nazionale di Geofisica e Vulcanologia, Pisa, Italy

24. Orsi G. (I,II,III,IV), Osservatorio Vesuviano, Istituto Nazionale di Geofisica e Vulcanologia, Naples, Italy

25. Papale P. (I,II,III,IV,V), sezione di Pisa, Istituto Nazionale di Geofisica e Vulcanologia, Pisa, Italy

26. Ricciardi G.P. (I,II,III), Osservatorio Vesuviano, Istituto Nazionale di Geofisica e Vulcanologia, Naples, Italy

27. Ricco C. (I), Osservatorio Vesuviano, Istituto Nazionale di Geofisica e Vulcanologia, Naples, Italy

28. Rinaldi A.P. (IV), sezione di Bologna, Istituto Nazionale di Geofisica e Vulcanologia, Bologna, Italy

29. Russo G. (I,III), Osservatorio Vesuviano, Istituto Nazionale di Geofisica e Vulcanologia, Naples, Italy

30. Saccorotti G. (II,III,IV,V), sezione di Pisa, Istituto Nazionale di Geofisica e Vulcanologia, Pisa, Italy

31. Sandri L. (II,III,IV,V), sezione di Bologna, Istituto Nazionale di Geofisica e Vulcanologia, Bologna, Italy

32. Sbrana A. (I), University of Pisa, Pisa, Italy

33. Scandone R. (III,IV,V), University of Rome "Roma 3", Rome, Italy

34. Scarlato P. (IV,V), sezione Roma 1, Istituto Nazionale di Geofisica e Vulcanologia, Rome, Italy

35. Scarpa R. (III,IV), University of Salerno, Salerno, Italy

36. Todesco M. (I,III,IV), sezione di Bologna, Istituto Nazionale di Geofisica e Vulcanologia, Bologna, Italy

\section{Abbreviations}

CFc: Campi Flegrei caldera; BET: Bayesian Event Tree; BET_EF: Bayesian Event Tree for Eruption Forecasting; BETEF_CF: Bayesian Event Tree for Eruption Forecasting, implemented for Campi Flegrei, Italy; VT: volcano tectonic events; LP: long-period event; VLP: very-long period event; ULP: ultra-long period event; CLVD: Compensated-Linear-Vector-Dipole event; RSAM: Real-time Seismic-Amplitude Measurement.

\section{Competing interests}

The authors declare that they have no competing interests.

\section{Authors' contributions}

JS coordinated the writing of the paper, prepared all relative materials, implemented software codes and performed the analysis. WM and JS conceived and co-led the elicitation experiment. PP coordinated the elicitation meetings with WM. LS participated in code development and data analysis. All authors read and approved the final manuscript. 


\section{Acknowledgements}

The work described in this paper has been carried out in the framework of the INGV-DPC projects Progetto V3: Ricerche sui vulcani attivi, precursori, scenari, pericolosità e rischio (2004-2006), and Progetto V1: UNREST - Realizzazione di un metodo integrato per la definizione delle fasi di unrest ai Campi Flegrei (20072009), funded by the Italian Civil Protection 'Dipartimento della Protezione Civile' (INGV-DPC 2005, 2007). The analysis of the background activity and the publication have been also supported by the project Quantificazione del MultiRischio con approccio Bayesiano: un caso studio per i rischi naturali della città di Napoli (2010-2013), funded by the Italian Ministry of Education, Universities and Research (Ministero dell'Istruzione, dell'Università e della Ricerca).

\section{Author details}

${ }^{1}$ Istituto Nazionale di Geofisica e Vulcanologia, sezione di Bologna, Via Donato Creti 12 - 40128 Bologna, Italy. ${ }^{2}$ Istituto Nazionale di Geofisica e Vulcanologia, sezione di Roma 1, Via di Vigna Murata, 605 - 00143 Rome, Italy. ${ }^{3}$ Istituto Nazionale di Geofisica e Vulcanologia, sezione di Pisa, Via della Faggiola, 32 - 56126 Pisa, Italy.

Received: 3 May 2012 Accepted: 5 November 2012

Published: 13 December 2012

\section{References}

Aspinall W (2006) Structured elicitation of expert judgment for probabilistic hazard and risk assessment in volcanic eruptions. In: Mader H, Coles S, Connor C, Connor L (eds). Statistics in Volcanology. Geological Society of London on behalf of IAVCEI, London. pp. 15-30

Barberi F, Corrado G, Innocenti F, Luongo G (1984) Phlegraean fields 1982-1984: Brief chronicle of a volcano emergency in a densely populated area. Bull Volcanology 47: 175-185

Bonafede M (1991) Hot fluid migration: an efficient source of ground deformation: application to the 1982-1985 crisis at Campi Flegrei-Italy. J Volcanology Geothermal Res 48: 187-198

Civetta L, Gasparini P (2012) Personal communication

Cook R (1991) Experts in Uncertainty: Opinion and Subjective Probability in Science. Oxford Univ. Press, New York

Cornish E (1977) The study of the future. World Future Society, Washington

Del Gaudio C, Aquino I, Ricciardi G, Ricco C, Scandone R (2010) Unrest episodes at Campi Flegrei: A reconstruction of vertical ground movements during 1905-2009. J Volcanology Geothermal Res 195: 48-56

De Siena L, Bianco F (2010) Seismic attenuation imaging of Campi Flegrei: Evidence of gas reservoirs, hydrothermal basins, and feeding systems. J Geophysical Res 115: B09312

di Vito MA, Lirer L, Mastrolorenzo G, Rolandi G (1987) The Monte Nuovo eruption (Campi Flegrei, Italy). Bull Volcanology 49: 608-615

Guidoboni E, Ciucciarelli C (2011) The Campi Flegrei caldera: historical revision and new data on seismic crises, bradyseisms, the Monte Nuovo eruption and ensuing earthquakes (twelfth century 1582 AD). Bull Volcanology 73: 655-677

INGV-DPC (2007) Progetto V1: UNREST - Realizzazione di un metodo integrato per la definizione delle fasi di unrest ai Campi Flegrei

INGV-DPC (2005) Progetto V3: Ricerche sui vulcani attivi, precursori, scenari, pericolosità e rischio

Lindsay J, Marzocchi W, Jolly G, Constantinescu R, Selva J, Sandri L (2010) Towards real-time eruption forecasting in the Auckland Volcanic Field: application of BET_EF during the New Zealand National Disaster Exercise 'Ruaumoko'. Bull Volcanology 72: 185-204

Linstone HA, Turoff M (1975) The Delphi Method: Techniques and Applications. Addison-Wesley Publishing Company Advanced Book Program, Reading

Mader H, Coles S, Connor C, Connor L(Eds) (2006) Statistics in Volcanology. Special Publications of IAVCEI. Geological Society of London on behalf of IAVCEI, London

Marzocchi W, Sandri L, Gasparini P, Newhall C, Boschi E (2004) Quantifying probabilities of volcanic events: the example of volcanic hazard at Mt. Vesuvius. J Geophysical Res 109: B11201

Marzocchi W, Sandri L, Selva J (2009) BET - Bayesian Event Tree model website. [http://bet.bo.ingv.it], last visited Dec. 2012.

Marzocchi W, Sandri L, Selva J (2008) BET_EF: a probabilistic tool for long- and short-term eruption forecasting. Bull Volcanology 70: 623-632
Marzocchi W, Woo G (2009) Principles of volcanic risk metrics: theory and the case study of Mt. Vesuvius and Campi Flegrei (Italy). J Geophysical Res 114: B03213

Neri A, Aspinall W, Cioni R, Bertagnini A, Baxter PJ, Zuccaro C, Andronico DBS, Cole P, Esposti Ongaro T, Hincks T, Macedonio G, Papale P, Rosi M, Santacroce R, Woo G (2008) Developing an Event Tree for probabilistic hazard and risk assessment at Vesuvius. J Volcanology Geothermal Res 178: 397-415

Newhall CG, Dzurisin D (1988) Historical Unrest at Large Calderas of the World, Vol. 2. U.S. Geological Survey Bulletin 1855, U.S. Government Printing Office, Washington

Newhall C, Hoblitt R (2002) Constructing event trees for volcanic crises. Bull Volcanology 64: 3-20

Orsi G, Civetta L, Del Gaudio C, de Vita S, di Vito MA, Isaia R, Petrazzuoli S, Ricciardi G, Ricco C (1999) Short-term ground deformations and seismicity in the nested Campi Flegrei caldera (Italy): an example of active block-resurgence in a densely populated area. J Volcanology Geothermal Res 91(2-4): 415-451

Orsi G, de Vita S, Di Vito MA (1996) The restless, resurgent Campi Flegrei nested caldera (Italy): constraints on its evolution and configuration. J Volcanology Geothermal Res 74: 179-214

Orsi G, Di Vito MA, Selva J, Marzocchi W (2009) Long-term forecast of eruption style and size at Campi Flegrei caldera (Italy). Earth Planetary Sci Lett 287: $265-276$

Sandri L, Guidoboni E, Marzocchi W, Selva J (2009) Bayesian event tree for eruption forecasting (BET_EF) at Vesuvius, Italy: a retrospective forward application to the 1631 eruption. Bull Volcanology 71: 729-745

Selva J, Marzocchi W, Sandri L (2009) Elicitation@CampiFlegrei website. http://bet.bo.ingv.it/elicitazione/elicitations.html, last visited Dec. 2012.

Selva J, Costa A, Marzocchi W, Sandri L (2010) BET_VH: Exploring the influence of natural uncertainties on long-term hazard from tephra fallout at Campi Flegrei (Italy). Bull Volcanology 72: 717-733

Selva J, Orsi G, Di Vito M, Marzocchi W, Sandri L (2012) Probability hazard map for future vent opening at the Campi Flegrei caldera, Italy. Bull Volcanology 74: $497-510$

doi:10.1186/2191-5040-1-5

Cite this article as: Selva et al:: Operational eruption forecasting at high-risk volcanoes: the case of Campi Flegrei, Naples. Journal of Applied Volcanology $2012 \mathbf{1}: 5$

\section{Submit your manuscript to a SpringerOpen ${ }^{\mathcal{O}}$ journal and benefit from:}

- Convenient online submission

Rigorous peer review

- Immediate publication on acceptance

- Open access: articles freely available online

- High visibility within the field

- Retaining the copyright to your article

Submit your next manuscript at $>$ springeropen.com 